\title{
Rancangan Aplikasi Pembelajaran Angklung Untuk SLB Bagian B Tuna Rungu Berbasis Android
}

\author{
Diana Effendi, Bella Hardiyana \\ Universitas Komputer Indonesia , Jl. Dipati Ukur No.112-116 Bandung 40132, Indonesia
}

\section{KEYWORDS}

Angklung, Partitur,Android, Deaf students

\section{CORRESPONDENCE}

Phone: 081320629213

E-mail: diana.effendi@email.unikom.ac.id

\section{INTRODUCTION}

Seni musik merupakan seni menata bunyi menjadi satu harmoni yang indah didengar yang terbagi menjadi musik klasik, tradisional dan modern[1]. Di dalam musik terdapat unsur-unsur musik yaitu nada, tangganada, tempo, ritme,dinamika dan harmoni[2].Terkait dengan musik anak memiliki beberapa ciri antara lain bentuknya yang sederhana, tema lagu disesuaikan dengan jiwa anak yang polos bahasa yang digunakan sederhana sehingga mudah dipahami anak-anak, lirik lagu yang tidak terlalu panjang dan mudah dihafal. Ansambel musik merupakan sebuah sajian musik yang dilakukan secara bersama-sama dengan menggunakan satu jenis atau berbagai jenis alat musik[3]. Angklung merupakan salah satu alat musik yang digunakan untuk pembelajaran ansambel musik anak. Angklung merupakan alat musik tradisional yang berkembang di msyarakat Indonesia, khusunya Jawa Barat. Alat musik ini terbuat dari bambu, sebuah tumbuhan yang sejak dulu akrab dikehidupan masyarakat Indonesia[4]. SLB N Cicendo merupakan salah satu sekolah yang menyelenggarkan pembelajaraan ansambel musik angklung bagi siswa-siswanya. Hal ini menarik, karena siswa SLB merupakan anak-anak yang memiliki kebutuhan khusus (ABK), dimana penanganan dalam pembelajaran memiliki penanganan khusus berbeda dengan penanganan anak pada umumnya. ABK tunarungu merupakan anak yang mengalami gangguan pendengaran yang meliputi seluruh gradai atau tingkatan ringan, sedang, berat dan sangat berat yang diakibatkan oleh organ pendengaran yang tidak berfungsi secara maksimal[5,6].
Dalam pembelajaran angklung di SLB N Cicendo dilakukan dengan menggabungkan Metode Demonstrasi dan Metode Maternal Reflektif (MMR).Metode Maternal Reflektif (MMR) merupakan metode pembelajaran bahasa yang pertama kali diperkenalkan oleh A. van Uden yang didasarkan pada cara seorang ibu mengajarkan bahasa pada anaknya melalui percakapan yang penuh kasih sayang, alamiah, spontan, serta menggunakan bahasa sehari-hari[7]. Guru mempraktekan secara langsung bagaimana memegang angklung, memainkan angklung dengan menggunakan bahasa isyarat. Pembelajaran musik angklung di SLB N Cicendo dengan menggabungkanABKdari semua tingkat jenjang sekolah. Guru melakukan penggabungan ABK di dalam pembelajaran musik angklung dikarenakan anggota untuk memainkan alat musik angklung berjumlah tidak sedikit. Oleh karena itu guru melakukan penggabungan ABK dalam berbagai jenjang di SLB N Cicendo. Saat ini terdapat 30 siswa yang mengikuti kegiatan angklung.

Namun, terdapat kendala dalam notasi sistem pengajaran angklung yang ada saat ini. Kurangnya simbol tangan yang mewakili notasi tertentu masih terbatas pada nada utama. Sehingga para peserta tidak dapat memainkan lagu yang didalmnya terdapat nada naik atau turun setengah karena belum terwakili oleh simbol tangan. Untuk menghasilkan nada yang harmonis antara melodi dan akor harus dilakukan oleh dua orang guru. Keterbatasan waktu dalam pelaksanaan pembelajaran angklung juga membuat pembelajaran angklung tidak terlaksana dengan baik. Pembelajaran angklung hanya diberikan satu bulan sekali dengan waktu yang relatif singkat, sekitar 30 menit atau hanya sekedar untuk selingan. 
Berdasarkan permasalahan tersebut, maka dibuatlah aplikasi multimedia pembelajaran angklung menggunakan perangkat lunak (software) Unity $3 \mathrm{~d}$ dengan basis aplikasi mobile (smartphone) ataupun desktop. Dengan dibuatkannya aplikasi multimedia interaktif tersebut, peserta didik dapat mempelajari angklung dengan mempelajari materi pengenalan angklung yang animatif, serta menyelesaiakan quiz dan games yang bisa diakses di rumah tanpa perlu ditemani oleh guru. Namun pembahasan kali ini hanya membahas mengenai bagaimana rancangan dari aplikasi pembelajaran angklung tersebut berbasis Android.

Aplikasi pembelajaran angklung berbasis Android dirancang untuk digunakan ketika peserta didik belajar angklung di rumah secara mandiri. User cukup menggerakkan perangkat mobile (smartphone) sebagai pengganti dari angklung. Metoda pembelajaran multimedia versi mobile ini berbentuk seperti tutorial, sehingga peserta didik dapat mempelajari angklung dari sangat dasar. Selain itu, terdapat fasilitas quiz dan games sehingga peserta didik dapat bermain sambil belajar angklung dengan lebih interaktif dan menyenangkan

\section{HASIL DAN PEMBAHASAN}

\section{Use Case Diagram}

Use case diagram merupakan pemodelan untuk kelakuan (behavior) sistem informasi yang akan dibuat [8]. Use case diagram dari rancangan sistem aplikasi yang dibuat tergambar pada gambar 1.

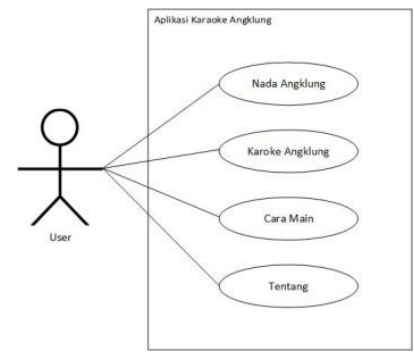

Gambar 1 Use Case Diagram Rancagan Aplikasi Pembelajran Angklung

\section{Skenario Use Case}

Skenario use case merupakan gambaran alur dari use case yang telah dibuat untuk memudahkan user dalam memahami jalan atau alur dari sistem yang akan diusulkan [8]. Berikut skenario use case dari sistem aplikasi pembelajaran angklung yang diusulkan.

\section{Skenario Usecase Nada Angklung}

\begin{tabular}{|c|c|c|}
\hline \multicolumn{3}{|c|}{ Identifikasi } \\
\hline Nomor & \multirow{2}{*}{\multicolumn{2}{|c|}{$\begin{array}{l}1 \\
\text { Nada Angklung }\end{array}$}} \\
\hline Nama & \multirow{2}{*}{\multicolumn{2}{|c|}{$\begin{array}{l}\text { Nada Angklung } \\
\text { User bisa memilih nada yangingin di bunvikan }\end{array}$}} \\
\hline Tujuan & & \\
\hline Aktor & \multicolumn{2}{|l|}{ User } \\
\hline \multicolumn{3}{|c|}{ SkenarioUtama } \\
\hline Kondisi Awal & \multicolumn{2}{|c|}{ User membuka aplikasi Karaoke Angklung } \\
\hline & Aksi Aktor & Reaksi Sistem \\
\hline \multicolumn{2}{|c|}{$\begin{array}{l}\text { 1)Menekan menu 'Nada Angklung' } \\
\text { 3)Menekannada yangingin di mainkan } \\
\text { 5)Menggoyangkan SMARTPHONE untuk } \\
\text { membunyikan nada }\end{array}$} & $\begin{array}{l}\text { 2)Menampilakan } 21 \text { nada dalam angklung } \\
\text { 4)Menampilakansimbolnada yang dipilih } \\
\text { 6)Mengeluarkan bunyinada }\end{array}$ \\
\hline
\end{tabular}

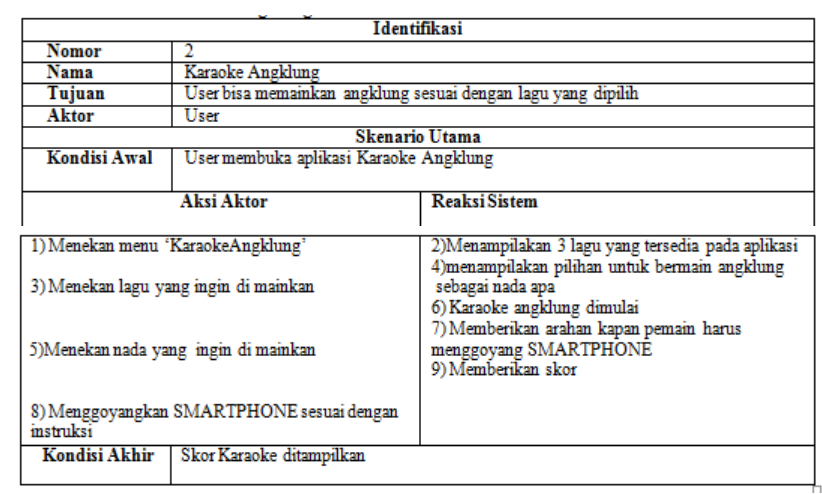

\begin{tabular}{|c|c|c|}
\hline \multicolumn{3}{|c|}{ Skenario Use case Cara Main } \\
\hline \multicolumn{3}{|c|}{ Identifikasi } \\
\hline Nomor & \multirow{2}{*}{\multicolumn{2}{|c|}{$\frac{3}{C \text { aramain }}$}} \\
\hline Nama & & \\
\hline Tujuan & \multicolumn{2}{|c|}{ Menjelaskan cara bermain dalam aplikasi ini } \\
\hline Aktor & \multicolumn{2}{|c|}{ User } \\
\hline \multirow{2}{*}{\multicolumn{3}{|c|}{$\begin{array}{c}\text { Skenario Utama } \\
\text { User membuka aplikasi Karaoke Angklung }\end{array}$}} \\
\hline & & \\
\hline \multicolumn{2}{|r|}{ AksiAktor } & ReaksiSistem \\
\hline \multicolumn{2}{|c|}{$\begin{array}{l}\text { 1) Menekan menu 'Cara Main' } \\
\text { 3) Menekan nada angklung yang ingin dibunyikan }\end{array}$} & $\begin{array}{l}\text { 2)Menampilakan nada dari angklung } \\
\text { 4) Mengeluarkan bunyi nada angklung }\end{array}$ \\
\hline Kondisiakhir & \multicolumn{2}{|c|}{ Nada angklung yang dipilih berbunyi } \\
\hline
\end{tabular}

\section{Skenario Use Case Tentang}

\begin{tabular}{|l|l|}
\hline \multicolumn{1}{|c|}{ Identifikasi } \\
\hline Nomor & Tentang \\
\hline Nujal & Menjelaskan tentang aplikasi Karaoke Angklung \\
\hline Aktor & User \\
\hline \multicolumn{2}{|c|}{ Skenario Utama } \\
\hline Kondisi Awal & User membuka aplikasi Karaoke Angklung \\
\hline Aksi Aktor & Reaksi Sistem \\
\hline 1)Menekan menu 'Tentang' & 2)Menampilakan informasi tentang aplikasi Karaoke Angklung \\
& \\
\hline Kondisi Akhir & Informasitentang aplikasi ditampilkan \\
\hline
\end{tabular}

\section{ACTIVITY DIGRAM}

Activity diagram digunakan untuk menggambarkan aliran kerja dari suatu sistem. Berikut activity diagram dari aplikasi angklung

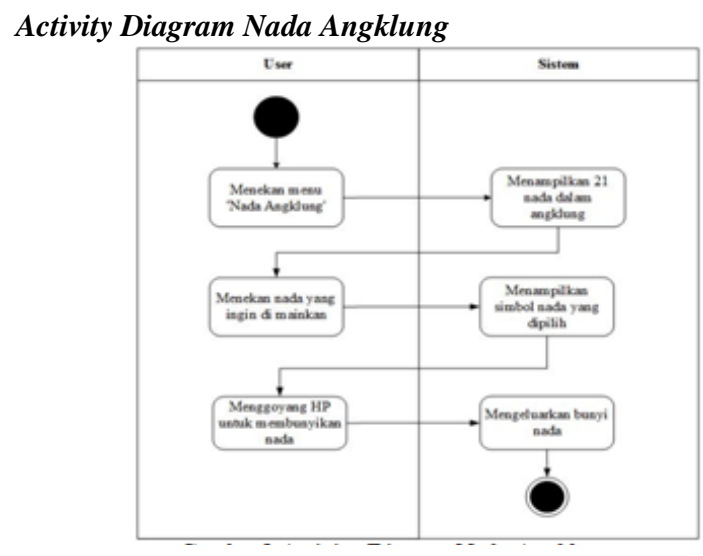

Gambar 2 Activity Diagram Nada Angklung

\section{Skenario Usecase Karaoke Angklung}


Activity Diagram Karaoke Angklung

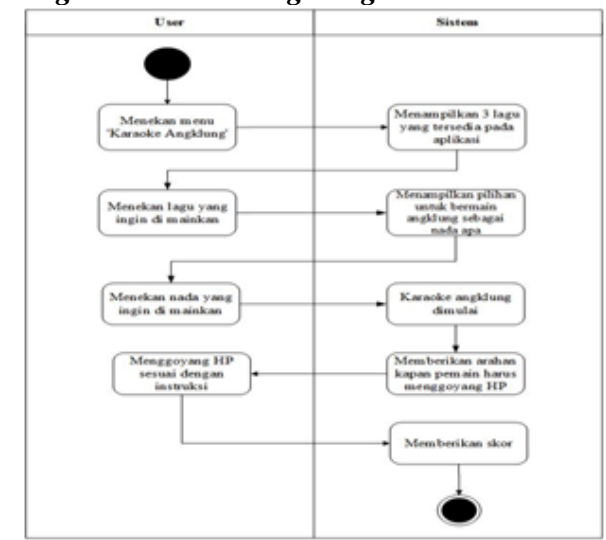

Gambar 3 Diagram Activity Karaoke Angklung

Activity Diagram Cara Main

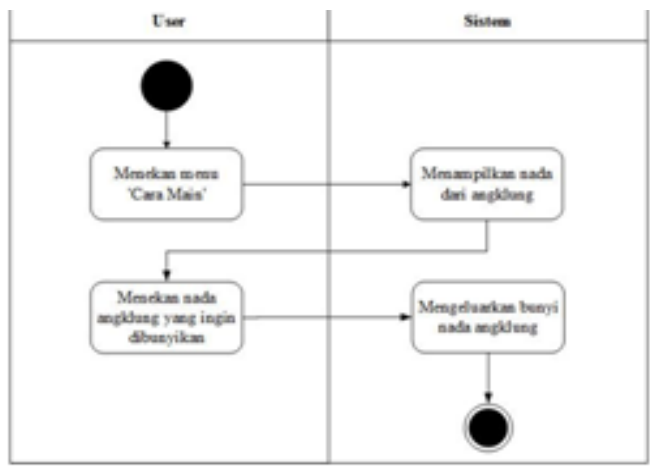

Gambar 4 Actity Diagram Cara Main

Activity Diagram Tentang

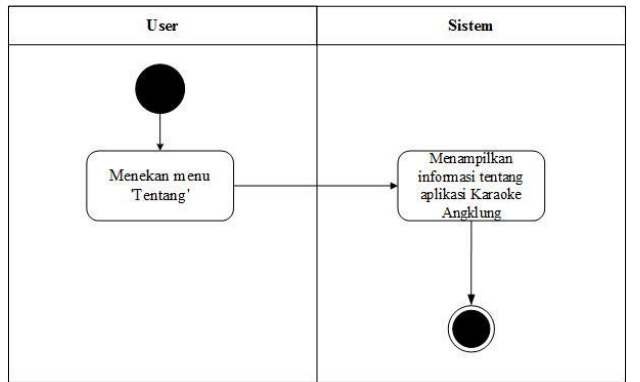

Gambar 5 Acitity Diagram Tentang.

\section{RANCANGAN INTERFACE APLIKASI}

Tampilan halaman utama aplikasi angklung ini tersaji pada gambar 6. Di halaman utama ini terdapat fasilitas nada angklung, karaoke angklung, cara main dan tentang.

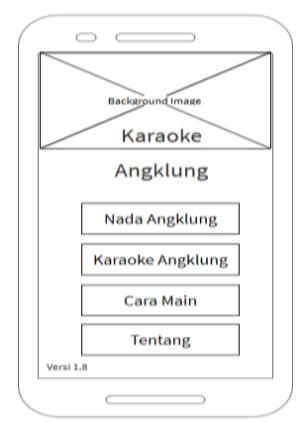

Gambar 6 Rancangan Halaman Utama Aplikasi Angklung
Sedangkan petunjuk bagaimana cara memainkan angklung menggunakan aplikasi ini terdapat pada menu cara main ( gambar 7)

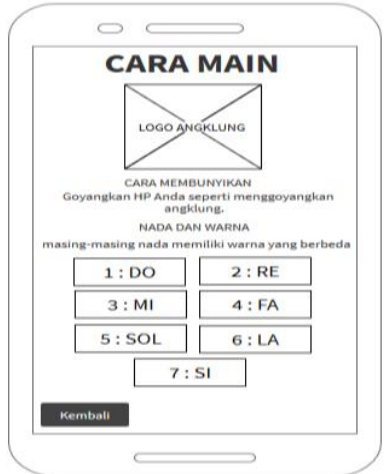

Gambar 7 Rancangan cara Main Aplikasi Angklung

Sedangkan di menu Nada Angklung akan ditampilkan 21 nada dalam angklung dari nada rendah (warna lebih terang), nada normal dan nada tinggi (warna lebih gelap). Nada tersebut bisa dipilih sesuai dengan keingan user (gambar 8)

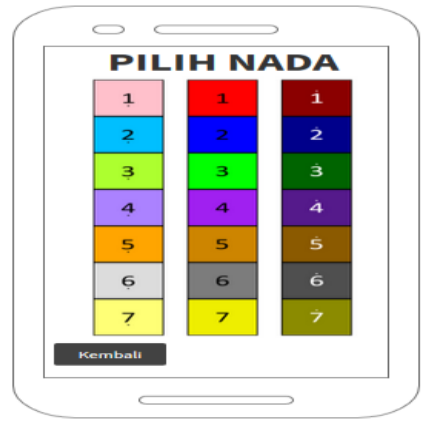

Gambar 8 Rancangan Pilihan Nada Angklung

Di layar smartphone akan ditampilkan simbol nada sesuai dengan nada yang telah dipilih sebelumnya dan smartphone akan berbunyi jika digoyangkan sesuai dengan tersebut. Gambar 13 merupakan contoh tampilan jika nada Do yang dipilih. Tampilan untuk nada yang lain sama dengan tampilan nada Do hanya symbol nada sesuai dengan yang dipilih oleh user.

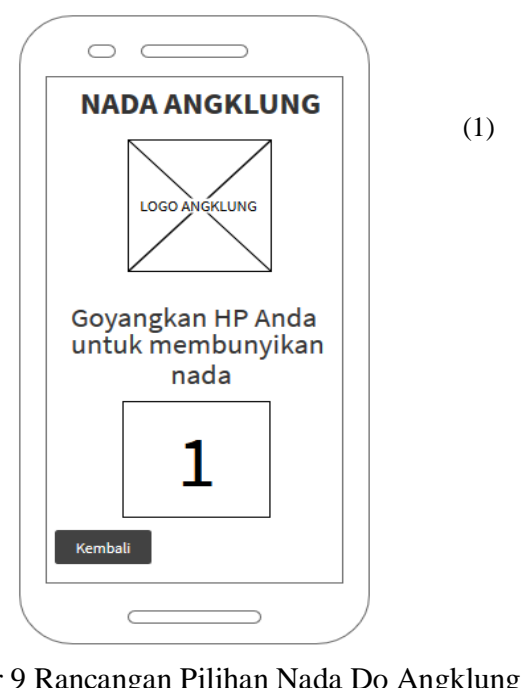

Gambar 9 Rancangan Pilihan Nada Do Angklung

Pada menu karaoke angklung akan ditampilkan tiga pilhan lagu yaitu Bunda mewakili lagu berbahsa Indonesia, I Have A Dream 
mewakili lagu berbahasa asing dan Penyeum Bandung mewakili lagu Sunda

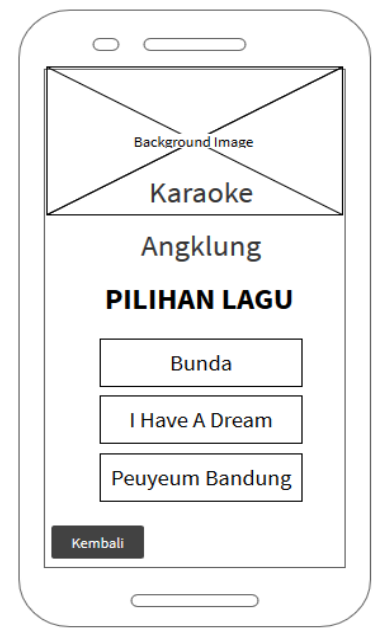

Gambar 10 Rancangan Pilihan Karaoke Aplikasi Angklung

Jika dipilih salah satu lagu, maka aplikasi akan menampilkan pilihan bermain sebagai angklung apa sesuai nada dasar. Contohnya jika dipilih Bermain Angklung Do, maka aplikasi akan memainkan semua nada angklung lagu Bunda, kecuali nada Do. Nada Do hanya berbunyi jika pemain menggoyangkan SMARTPHONE. Hal ini berlaku untuk lainnya.

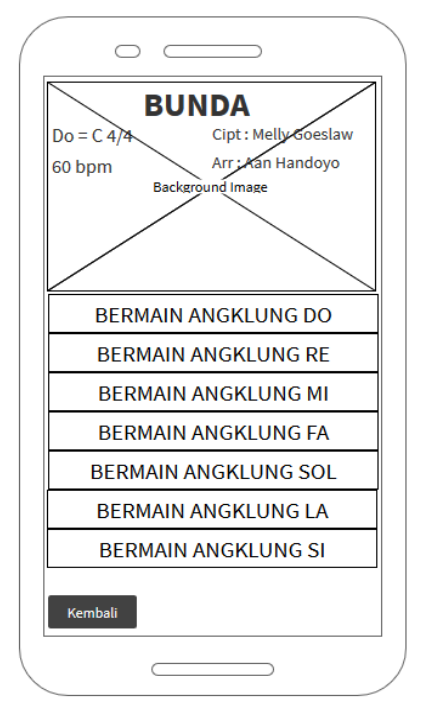

Gambar 11 Rancangan Karaoke Angklung Lagu Bunda

Diaplikasi ini akan diberikan arahan, kapan user harus menggoyangkan smartphone ataupun tidak (smartphone diam). Jika pemain berhasil menggoyangkan smartphone sesuai dengan instruksi, maka aplikasi akan memberikan skor.

\section{CONCLUSIONS}

Rancangan aplikasi karaoke angklung versi android ini dimaksudkan bagaimana user untuk latihan di rumah. Dimana user cukup menggoyahkan smartphone seolah-olah seperti sedang memainkan angklung. Aplikasi ini dirancang dimana aplikasi akan mengeluarkan suara seperti angklung aslinya, sesuai dengan nada yang dipilih oleh user. Diahrapkan rancangan ini nantinya akan diimplementasikan menggunakan program unity $3 \mathrm{~d}$ dan dapat dioperasikan di smartphone bersistem operasi Android minimal versi KitKat

\section{UCAPAN TERIMA KASIH}

Penelitian ini merupakan bagian dari Program Kemitraan Masyarakat (PKM) yang didanai Kementrian Riset, dan Teknologi, Tahun Anggaran 2019.

\section{REFERENCES}

[1] Nursantara, Yayat. 2002. Seni Budaya untuk SMA Kelas $X$. Jakarta : Erlangga.

[2] Suwandi, dkk.2007. Berkarya Seni Budaya untuk SMP Kelas VII. Jakarta: Ganeca Exact.

[3] Setyobudidkk. 2002. Seni Budaya untuk SMP Kelas VIII. Jakarta :Erlangga.

[4] Indah,Dwi. 2016. Pembelajaran Ansambel Musik Angklung Di SLB C Negeri Pembina Kalimantan Selatan, Pelataran Seni Vol 1, No. 1, 11-18.

[5] Effendi, Diana.,2014. Learning Application Using Multimedia For $5^{\text {th }}$ Graders Elementary School Student about "Photosynthesis in Plants", Proceding The $1^{\text {st }}$ Sriwijaya University Learning and Education International Conference (SULE-IC), ISBN : 987-60270378-0-9, pp.927-934.

[6] Effendi, Diana., Program Aplikasi Pembelajaran IPA Materi Sistem Peredaran Darah Manusia untuk Siswa Kelas V SDLB Bagian B (Tuna Rungu) Berbasis Multimedia, Prosiding SNETE ke-4 Jurusan Teknik ElektroUniversitasUnsyiah Banda Aceh, ISSN : 20889984, pp.5-10, August, 2014.

[7] Bunawan, L., \&Yuwati. 2000. Penguasaan Bahasa Anak Tunarungu. Jakarta: Yayasan Santirama.

[8] Sukamto, Rosa Ariani, Shalahudin, Mhd. 2011. Modul Pembelajaran Rekayasa Perangkat Lunak (Terstruktur dan Berorientasi Objek), Modula, Bandung. 